v.23, n.3, Especial do $3^{\circ}$ Workshop de Nutrição de Animais Selvagens da AZAB, p.17-20, 2018

\title{
Condição nutricional e sugestão de padrão alimentar para Chelonoidis sp ${ }^{1}$
}

\section{CASTRO, Isabella Rigo Werneck de ${ }^{2}$, PINKE TESTA, Carolyne Assis Eigenheer ${ }^{3}$, SILVA, Diogo Cristo} Silva $e^{4}$, SANTOS, Gisele Junqueira dos ${ }^{3}$, HIPPÓLITO, Alícia Giolo ${ }^{3}$, MELCHERT, Alessandra ${ }^{5}$

\footnotetext{
${ }^{1}$ Iniciação Científica do primeiro autor.

${ }^{2}$ Graduando do curso de Zootecnia - Faculdade de Medicina Veterinária e Zootecnia, UNESP, Botucatu/SP, Brasil.

${ }^{3}$ Doutorando do Programa de Pós-Graduação em Animais Selvagens - Faculdade de Medicina Veterinária e Zootecnia, UNESP, Botucatu/SP, Brasil.

${ }^{4}$ Mestrando do Programa de Pós-Graduação em Animais Selvagens - Faculdade de Medicina Veterinária e Zootecnia, UNESP, Botucatu/SP, Brasil.

${ }^{5}$ Docente - Departamento de Clínica Veterinária, Faculdade de Medicina Veterinária e Zootecnia, UNESP, Botucatu/SP, Brasil.

Email: carolyne.pinke@gmail.com
}

RESUMO: Objetivou-se com esse trabalho realizar a avaliação nutricional e a sugestão de um padrão alimentar para o gênero Chelonoidis sp., usando dados biométricos como o peso, o escore de condição corporal, o comprimento e a largura do casco e do plastrão. Foram utilizados 52 híbridos, de jabuti-piranga (Chelonoidis carbonaria) e jabuti-tinga (Chelnoidis denticulata), sendo 27 machos e 25 fêmeas. A dieta fornecida foi uma combinação de fontes de proteína, leguminosas, verduras e frutas disponíveis no local para observação do consumo e comportamento alimentar individual. Com base nisso, eles foram classificados de acordo com o aspecto casco, preferência alimentar e escore de condição corporal, o que refletiu no efeito de dominância e frequência alimentar por meio da observação dos jabutis em 12 momentos. Para a análise estatística dos dados foram utilizados os procedimentos de análise de variância (ANOVA) one way e posteriormente aplicado o teste de Tukey, sendo considerado o nível de significância quando $P<0,05$. A frequência de alimentação dos animais foi determinada como um padrão para distinguir animais obesos de desnutridos. A alocação conjunta dos jabutis em cativeiro promove efeito de dominância no comportamento alimentar e o estado nutricional dos animais foi variável e a preferência alimentar é por fontes de proteína, porém a necessidade de inclusão é de no máximo $5 \%$ na dieta dos animais, com o mínimo de $15 \%$ e máximo de $35 \%$ de proteína bruta na matéria seca.

Palavras-chave: comportamento alimentar; dados biométricos; escore de condição corporal; jabutis.

\section{INTRODUÇÃO}

O Chelonoidis carbonarius e o Chelonoidis denticulatus são animais onívoros e/ou carnívoros (FERREIRA et al., 2012), ectodérmicos e, por este motivo, se atêm à temperatura do ambiente, assim obtendo o calor necessário para a regulação dos processos fisiológicos de fontes externas, podendo deglutir pedras e grãos de areia que auxiliam na motilidade intestinal (PESSOA, 2009). Possuem uma digestão lenta para melhor aproveitamento dos nutrientes pelo organismo e, em condições adversas, interrompem a ingestão de alimentos (BJORDNAL, 1989). Em tempos frios, apresentam níveis de sonolência e ócio, diminuindo as 
funções vitais, fato este imprescindível à sobrevivência. Entretanto, em períodos quentes, tendem a se mobilizar e comer mais, como um fator compensatório do período mais frio (TORRES, 2012). Transtornos nutricionais, como obesidade, foram observadas por Jodice et al. (2006) e a deformidade no casco trata-se de uma condição de desnutrição, associada à anorexia, que é comumente observada em jabutis (RODRIGUES, 2011).

Assim, este trabalho teve como objetivo avaliar a condição nutricional do gênero Chelonoidis sp., mantidos em cativeiro após abandono ou captura, correlacionando a condição corporal com o efeito de dominância de acordo com a frequência e preferência alimentar.

\section{MATERIAL E MÉTODOS}

A pesquisa foi realizada no Centro de Medicina e Pesquisa em Animais Selvagens (CEMPAS), da Faculdade de Medicina Veterinária e Zootecnia, UNESP, Botucatu/SP. O experimento foi submetido e autorizado pela Comissão de Ética no uso de Animais (CEUA), no 129/2015 FMVZ/UNESP.

Foram utilizados 52 híbridos de C. carbonarius e $C$. denticulatus, sendo 27 machos e 25 fêmeas. Os animais foram identificados numericamente no casco, através de corretivo líquido, fixado com spray de verniz. Foram alocados em um único recinto com formato quadrado, descoberto e que recebia incidência de energia solar durante todo o período diurno. O cocho para alimentação ficava em uma de suas extremidades e o bebedouro na parte central, sendo o chão de terra batida. A dieta ofertada combinava fontes de proteínas (ovos cozidos, pescoço de frango cru, ração canina umedecida, ração felina umedecida), verduras (alface, couve), legumes (beterraba ralada, cenoura ralada, batata-doce cozida, milho com espiga) e frutas (banana, maçã, mamão, manga) disponíveis no local. A cada dia era ofertado somente um tipo de alimento de cada classe, ou seja, a cada dia era escolhido somente uma fonte de proteína, uma verdura, um legume e uma fruta. Os animais foram pesados em balança comum, o comprimento e a largura de casco e plastrão foram medidos com fita métrica. Foi anotada a ordem de preferência pelos grupos alimentares (proteínas $>$ frutas $>$ legumes> verduras) e a ingestão de água. Os animais foram divididos em dois grupos de acordo com a dominância (dominantes - D ou submissos - S), frequência de alimentações e escore de condição corporal (magro - $\mathrm{M}$, normal $\mathrm{N}$ ou obeso - O) (NORTON \& WYNEKEN, 2015). O período experimental foi de 57 dias, duas observações por semana, com uma média de 120 minutos em cada observação, entre os meses de agosto e setembro de 2016, totalizando 12 momentos. Para a análise estatística dos dados foram utilizados a análise de variância one way e, posteriormente, 0 teste de Tukey, sendo considerado o nível de significância de $5 \%$ (Processo CEUA nำ129/2015 - FMVZ/UNESP).

\section{RESULTADOS E DISCUSSÃO}

Os grupos, segundo a dominância, apresentaram pesos com valores médios próximos $(D=5,26 \mathrm{Kg} \pm$ $2,3 ; \mathrm{S}=4,46 \mathrm{Kg} \pm 1,5)$, assim como as medidas do casco, (comprimento: $\mathrm{D}=$ $41 \mathrm{~cm} \pm 7,2 ; \mathrm{S}=39,1 \mathrm{~cm} \pm 5,8 /$ largura $\mathrm{D}=36,5 \mathrm{~cm} \pm 7,6 ; \mathrm{S}=33 \mathrm{~cm} \pm 5,3)$. Quanto ao plastrão, ocorreu diferença estatística $(P<0,05)$ no seu comprimento $(D=26,5 \mathrm{~cm} \pm 6,9 ; S=23,3 \mathrm{~cm} \pm 2,9)$, mas não ocorreu na sua largura $(D=$ $21,2 \mathrm{~cm} \pm 6,3 ; \mathrm{S}=18,8 \mathrm{~cm} \pm 2,5)$.

O escore de condição corporal $(D=3,2 \pm 0,9 ; S=2,8 \pm 0,8)$ também não 
apresentou diferença estatística significativa. Os dominantes demonstraram maior $(P<0,0001)$ frequência alimentar em relação aos submissos $(D=8,8 \pm 1,7 ; S=4,8 \pm 1,2)$. Segundo a condição corporal, os indivíduos obesos apresentaram valores maiores $(P<0,0001)$ de peso $(M=3,9 \mathrm{Kg}$ $\pm 0,8 ; \mathrm{N}=4,4 \mathrm{Kg} \pm 1,9 ; \mathrm{O}=6,7 \mathrm{Kg} \pm 0,5)$, comprimento $(\mathrm{M}=36,6 \mathrm{~cm} \pm 3,8 ; \mathrm{N}=$ $38,5 \mathrm{~cm} \pm 5,5 ; \mathrm{O}=47,1 \mathrm{~cm} \pm 6,8)$ e largura do casco $(\mathrm{M}=31,3 \mathrm{~cm} \pm 3,3 ; \mathrm{N}=$ $33,5 \mathrm{~cm} \pm 5,4 ; \mathrm{O}=42,2 \mathrm{~cm} \pm 6,8) \mathrm{em}$ relação aos animais magros e normais. O comprimento do plastrão $(\mathrm{M}=22,7 \mathrm{~cm}$ $\pm 1,6 ; \mathrm{N}=25,1 \mathrm{~cm} \pm 7,5 ; \mathrm{O}=28 \mathrm{~cm} \pm 3,8$ ), nos obesos, foi significativamente maior $(P<0,05)$, mas a sua largura $(M=18,3 \mathrm{~cm}$ $\pm 1,8 ; \mathrm{N}=20,2 \mathrm{~cm} \pm 7 ; \mathrm{O}=22,4 \mathrm{~cm} \pm 3$ ) não apresentou diferença estatística.

Segundo Flosi et al. (2001), ao retirarmos um animal de seu habitat natural e intoduzí-lo em um ambiente sob os cuidados humanos, ele pode sofrer impactos em seu metabolismo, devido ao sistema imune comprometido, tornando-o propenso à doenças comumente relacionadas às desordens nutricionais. Os dois grupos apresentaram médias de pesos próximas, assim como as medidas de comprimento e largura do casco. Ocorreu uma diferença no comprimento de plastrão, bem como ao escore de condição corporal.

Em relação à frequência de alimentação, dado obtido mais visível, os dominantes demonstraram maior frequência em relação aos submissos. $A$ preferência alimentar por proteína foi unânime nos três grupos. A questão da escolha alimentar pelo gênero Chelonoidis sp. foi relatada por Mora \& Rugeles (1981), que relataram que os animais utilizaram o olfato e a visão para a localização dos alimentos. Malvasio et al. (2003), destacou que o olfato tem a função primordial para preferência, uma vez que, mesmo desprovidos da visão, os animais ainda se aproximaram de fontes protéicas ofertadas, como carne e sardinha, e não se manifestaram quando oferecido somente frutas e verduras.

\section{CONCLUSÃO}

A alocação conjunta dos jabutis em cativeiro promove efeito de dominância no comportamento alimentar e o estado nutricional dos animais foi variável. A preferência alimentar é por fontes de proteína, porém a necessidade de inclusão é de no máximo $5 \%$ na dieta dos animais, com o mínimo de $15 \%$ e máximo de $35 \%$ de proteína bruta na matéria seca.

\section{AGRADECIMENTOS}

Os autores agradecem ao Centro de Medicina e Pesquisa de Animais Selvagens - CEMPAS pela disponibilidade dos animais para este trabalho.

\section{REFERÊNCIAS}

BJORDNAL, K. A. Flexibility of digestive responses in two generalist herbivores, the tortoises Geochelone carbonaria and Geochelone denticulate. Oecologia, 1989.

FERREIRA, V.H.M.; JÚNIOR, M.C.; CHAGAS, C.F.; NONATO, I.A.; PIRES, S.T. Distocia em Jabuti Piranga (Chelonoidis carbonaria) - relato de caso. PUBVET, Londrina, V. 6, N. 36, Ed. 223, Art. 1479, 2012.

FLOSI, F. M.; GARCIA, J. M.; PUGLIESE. c.; SANCHEZ, A. A.; KLAJ, A. Manejo e enfermidades de quelônios brasileiros no cativeiro doméstico. Rev. educo contin. CRMV-SP/ Continuous Education Journal CRMV-SP, São Paulo. V. 4., p. 65 - 72. 2001.

JODICE, P. G. R.; EPPERSON, D. M.; HENKVISSER, G. Daily energy 
expenditure in free-ranging gopher tortoises (Gopherus polyphemus). BIOONE Online Journals Access Control. Institute of Animal Nutrition, Veterinary Faculty, University of Zurich, Zurich, Switzerland. v. 2006, n. 1. feb. 2006. p. 129-136.

MALVASIO, A.; DE SOUZA, A. M.; MOLINA, F. B.; SAMPAIO, F. A. Comportamento e preferência alimentar em Podocnemis expansa (Schweigger), $P$. unifilis (Troschel)) e $P$. sextuberculata (Cornalla) em cativeiro (Testudines, Pelomedusidae). Revista Brasileira de Zoologia, v. 20, n. 1, p. 161-168, 2003.

MORA, O. V. C.; RUGELES, M. L. Estudio comparativo del comportamiento de dos espécies de Morrocoy: Geochelone carbonaria y Geochelone denticulata y aspectos comparables de su morfologia externa. Cespedesia, v. 10, n. 37-38, 1981.

NORTON, T.; WYNEKEN, J. Body condition scoring the sea turtle. LafeberVet. 2015. Disponível em: $<w w w$.lafeber.com/vet/body-conditionscoring-the-sea-turtle/ \#References>. Acesso em 02 Mai 2016.

PESSOA, C.A. Avaliação da microbiota bacteriana e fúngica presente na cloaca de jabutis (Geochelone carbonaria) criados em domicílio e análise do potencial risco à saúde humana. São Paulo-SP, 2009.

RODRIGUES, S.S. Avaliação coproparasitológica de Chelonoidis carbonaria (SPIX, 1824) (Reptilia, Testudinidae) em cativeiro no Espírito Santo, 2011.

TORRES, R. S. Adaptações evolutivas: aspectos comportamentais, mecanismos de defesa e predação em répteis, 2012.
Agradecemos ao apoio da Fundação Araucária e da Coordenação de Aperfeiçoamento de Pessoal de Nível Superior - CAPES na realização do $3^{\circ}$ Workshop de Nutrição de Animais Selvagens.
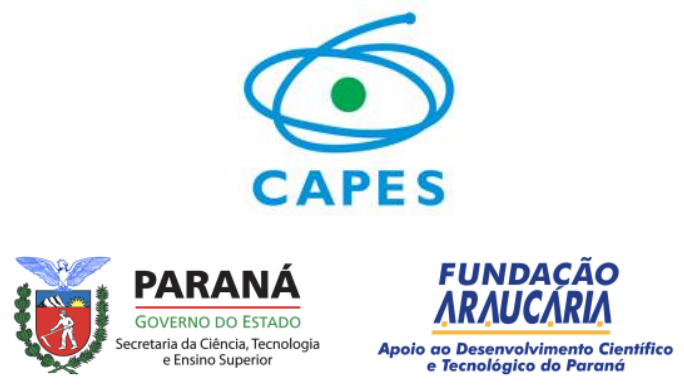